\title{
Макєঠovıкá
}

Tóp. 36 (2007)

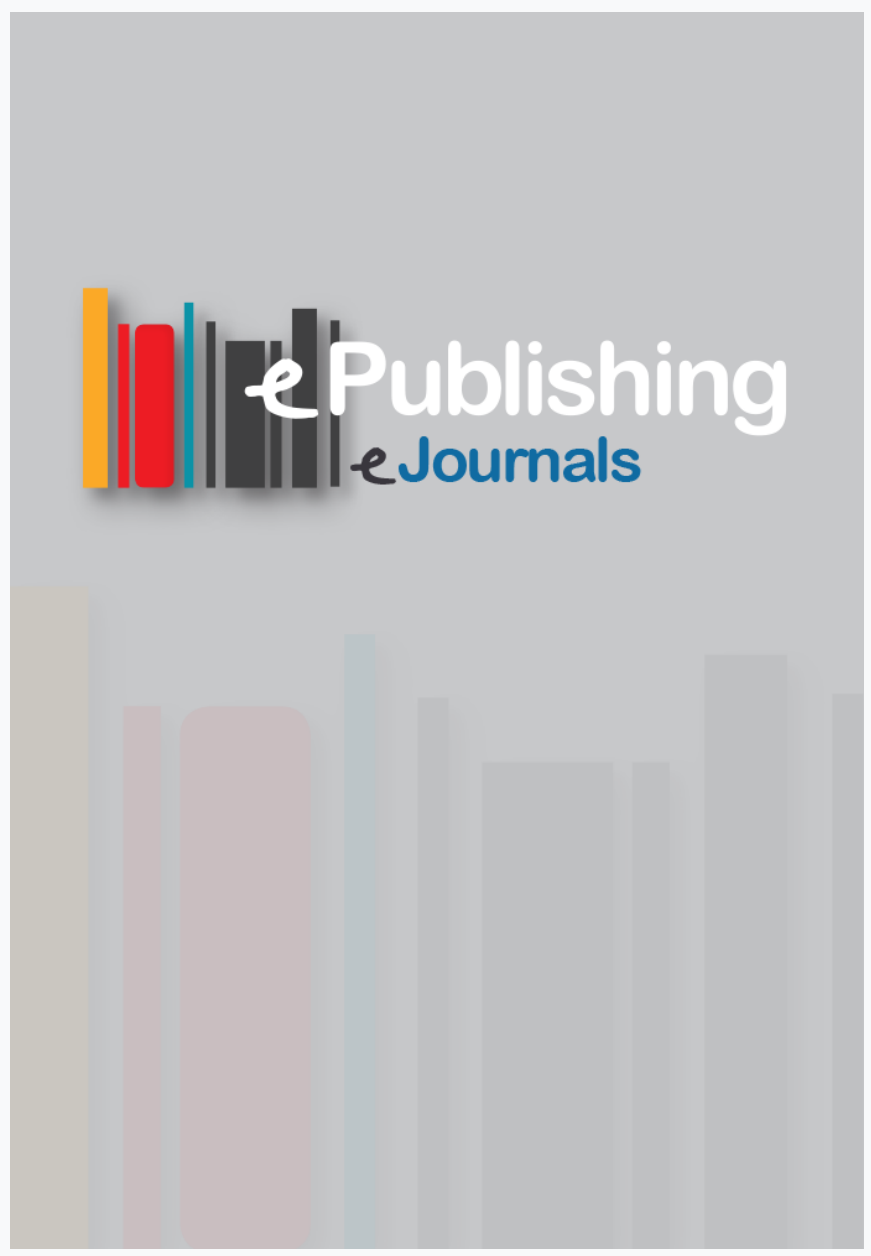

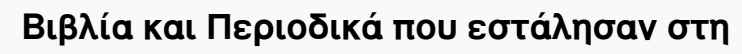

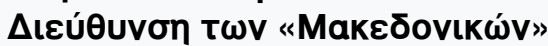

\section{Makedonika Makedonika}

doi: $10.12681 /$ makedonika.43

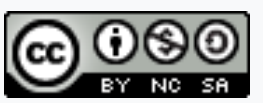

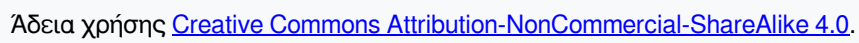

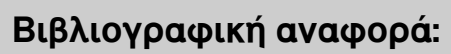

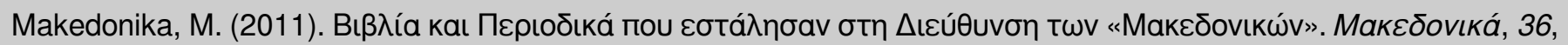
299-302. https://doi.org/10.12681/makedonika.43 


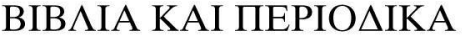

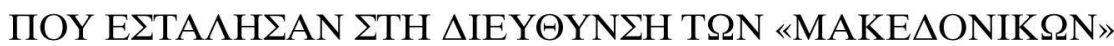

\section{$\mathrm{A}^{\prime} \mathrm{BIB} \Lambda \mathrm{IA}$}

Actes de Vatopédi, t. 2, de 1330 à 1376, édité par Jacques Lefort, Vasiliki Kravari, Christophe Giros et Kostis Smirlis, Paris, P. Lethielleux [coll. Archives de l'Athos XXII], 2006, $\sigma \sigma .518$.

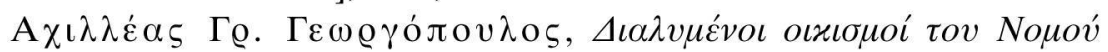

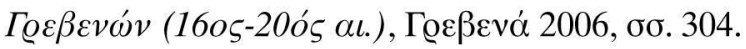

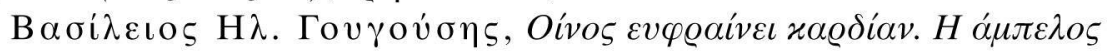

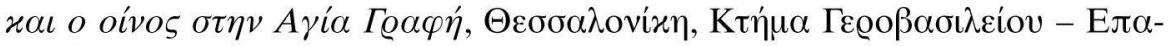

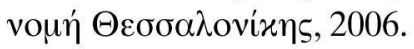

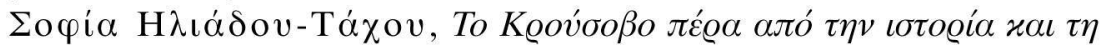

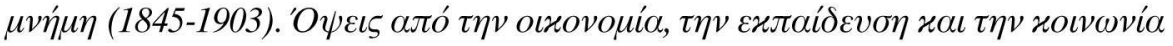

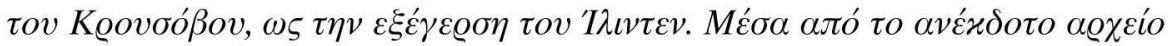

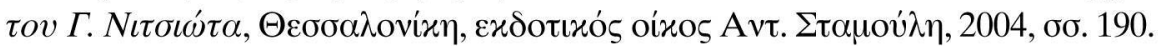

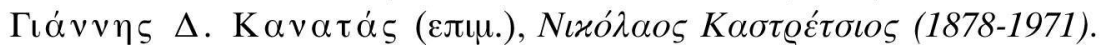

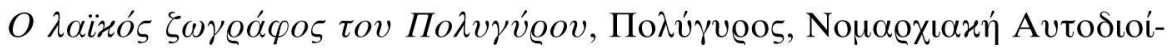

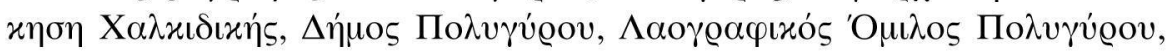
бо. 151.

Kostadin Kisyov, Thrace and Greece in ancient times. Part 1. Classical age tumuli in the municipality of Kaloyanovo, Plovdiv 2005, бo. 1119, лiv. I-XXIX.

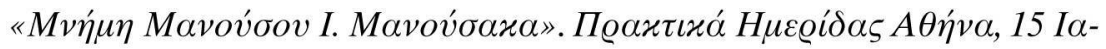

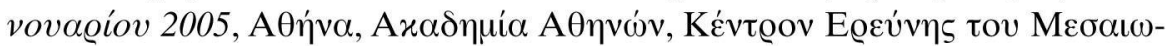

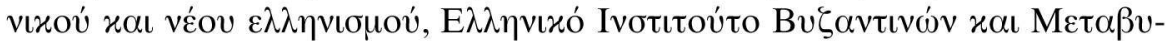

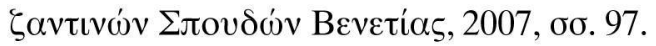

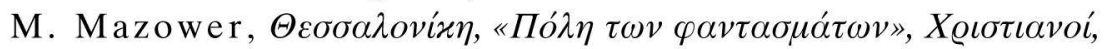

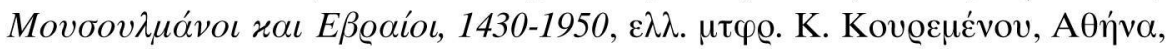

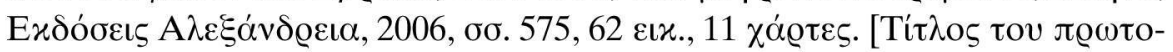

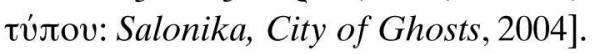

Vanče Stojčev, Military History of Macedonia, Skopje, Military Academy «General Mihailo Apostolski», 2004, бб. 770 (with a supplement, Maps, бб. 136).

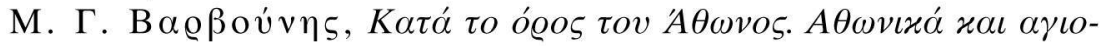

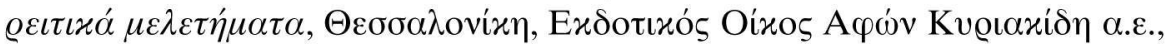
2006, бб. 416. 


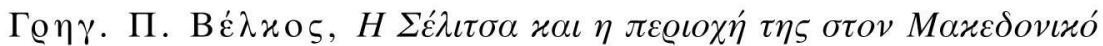

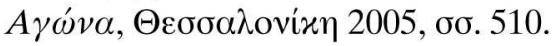

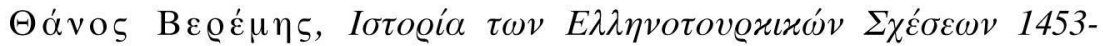

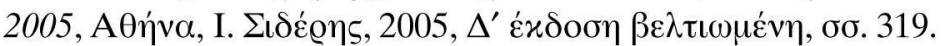

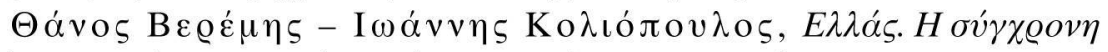

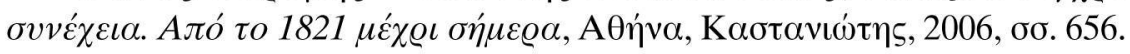

\section{B' $^{\prime}$ ПEPIO $\triangle \mathrm{IKA}$}

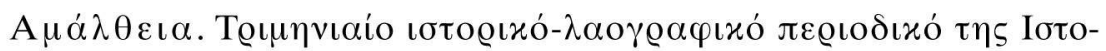

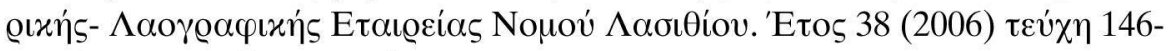

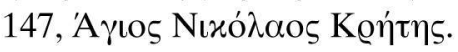

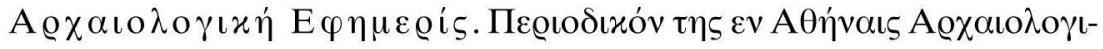

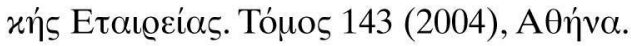

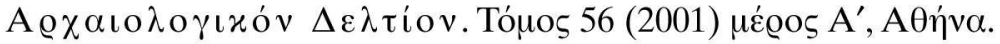

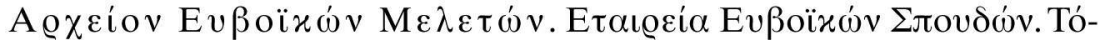
$\mu \circ 530$ (2006), 31 (2007), A $\theta \dot{v} v \alpha$.

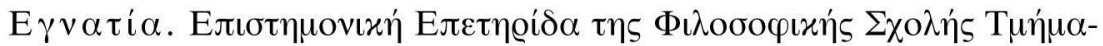

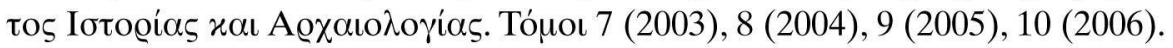

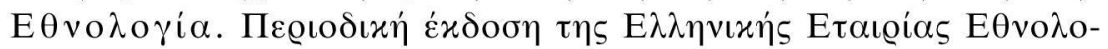

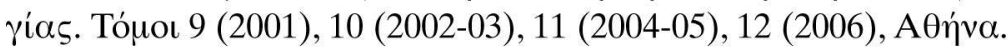

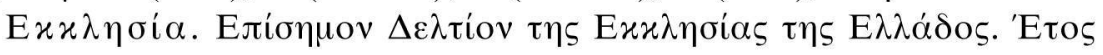

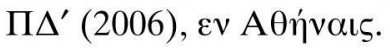

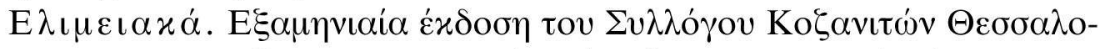

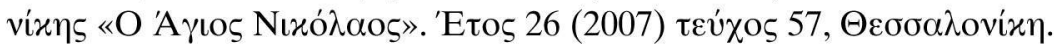

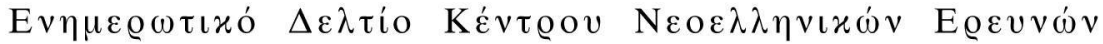

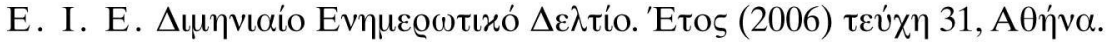

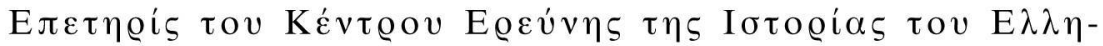

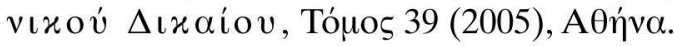

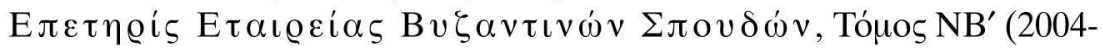
06), Аөท́val.

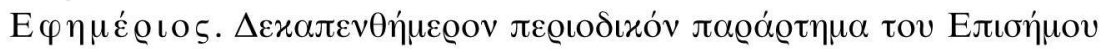

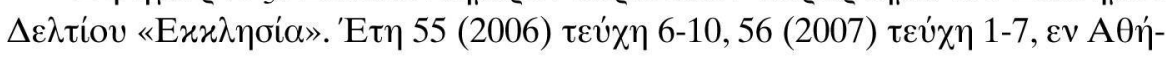
vals.

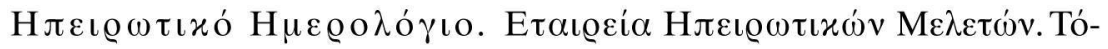
$\mu \circ \varsigma \mathrm{KE}^{\prime}$ (2006), I $\omega \alpha \dot{v} v v \iota v \alpha$.

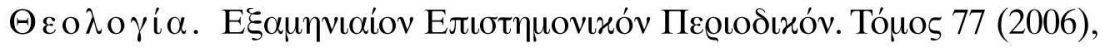
$\varepsilon v$ A $\theta$ ท́vaıs.

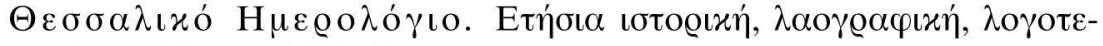

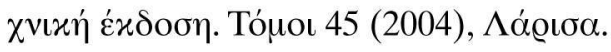




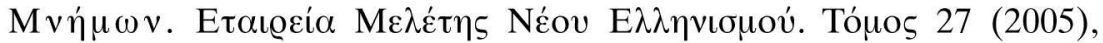
A $\theta$ ịval.

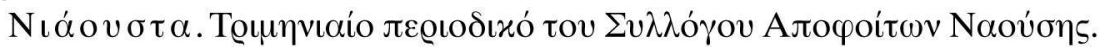

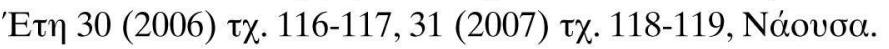

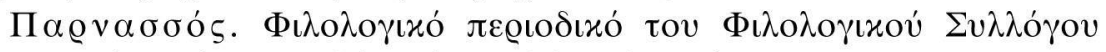

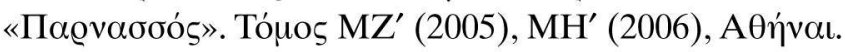

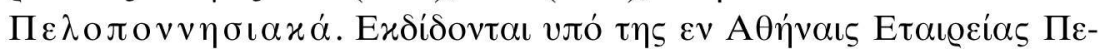

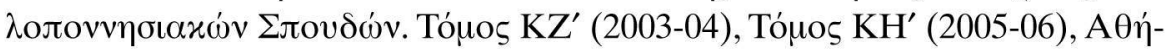
val.

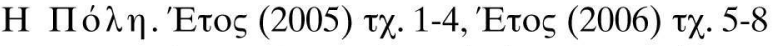

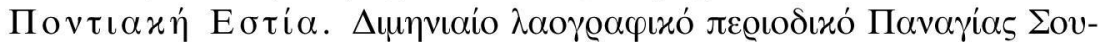

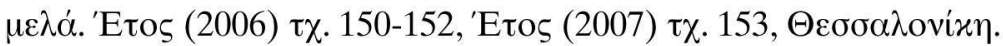

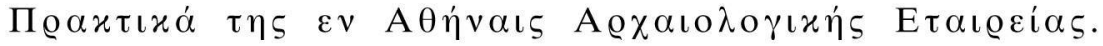
'Eтos 2004, A $\theta$ ท́va.

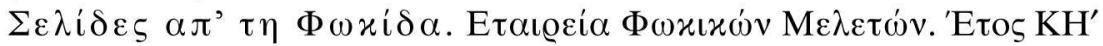

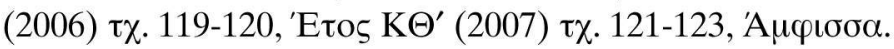

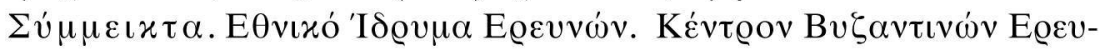
vóv. Tó

Analecta Bollandiana. Revue critique d'hagiographie trimestrielle. Tome 125 (2007) Fasc. 1, Bruxelles.

The Annual of the British School at Athens. Year (2005) no 100, Year (2006) no 101, London.

A pulum. Acta Musei Apulensis: Arheologie, Istorie, Etnografie. Vol. 43 (2006), Alba Iulia.

The Bodleian Library Record. Vol. XIX (2006), Nr 1-2, Oxford.

Bulgarian Historical Review. Research Quarterly Organ of the United Centre for History at the Bulgarian Academy of Sciences. Year 34

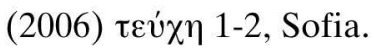

Byzantine and Modern Greek Studies. Centre for Byzantine, Ottoman and Modern Greek Studies, University of Birmingham. Vol. 31 (2007).

Études Balkaniques. Académie Bulgare des Sciences. Institut d'Études Balkaniques. Année 42 (2006) no 1-4, Année 43 (2007) no 1, Sofia.

Hesperia. Journal of the American School of Classical Studies at Athens. Vol. 75 (2006) no 2-4, Vol. 76 (2007) no 1-2, Athens.

Historical Abstracts. Bibliography of the World's Historical Literature. Vol. 57 (2006), Santa Barbara, California.

Jahrbuch der Österreichischen Byzantinistik. Österreichischen Akademie der Wissenschaften. Band 54 (2004), 55 (2005), 56 (2006), Wien. 
Journal of Hellenic Studies. Vol. 126 (2006), 127 (2007), London.

Makedonski Pregled. Spisanie za Nauka, literarura i Obštestven život. Godina 29 (2006) kn 1-4, 30 (2007) kn 1, Makedonskijat Naucen Institut, Sofija.

Mélanges de l'École Française de Rome (MEFRA). Tome 118 (2006), Rome.

Mittheilungen des Deutschen Archäologischen Instituts Athenische Abteilung. Band 120 (2005), Berlin.

Revue des Études Byzantines. Institut Français d'Études Byzantines. Tome 63 (2005), 64-65 (2006-07), Paris.

Revue des Études Grecques. Publication trimestrielle de l' Association pour l'Encouragement des Études Grecques. Tome 119 (2006) no 12, Tome 120(2007) no 1, Paris.

Revue des Études Sud-Est Européennes. Publié par l'Académie des Sciences Sociales et politiques. Institut d'Études Sud-Est Européennes. Tome 44 (2006) no 1-4, Bucuresti.

Rivista di Archeologia. Publicazione annuale diretta da Gustavo Traversari. Università degli studi. Anno XXIX (2005), Venezia.

Starinar. Organ Arheoloskog Instituta-Starinar: Institut Archéologique. Srpska Akademija Naukal. Tom. 53-54 (2003-04), Beograd.

Vestnik Drevnej Istorii. Rossijskaja Akademija Nauk. Institut Vseobsej Istorii. Vol. (2006) no 1-4, Vol. (2007) no 1-2, Moskva.

Zbornik Radova. Vizantinoloskog Instituta. Tomes 38 (1999-2000), 39 (2001-02), 40 (2003), 41 (2004), 42 (2005), 43 (2006), Beograd. 